I Universidade Federal do Rio de Janeiro (UFRJ),

Departamento de Sociologia, Rio de Janeiro, RJ, Brasil

brunovcardoso@hotmail.com

II Universidade Federal Fluminense (UFF), Departamento de Sociologia

e Metodologia em Ciências Sociais, Niterói, RJ, Brasil

velosohirata@gmail.com

Bruno Cardoso'

Daniel Hirata"

\title{
DISPOSITIVOS DE INSCRIÇÃO E REDES DE ORDENAMENTO PÚBLICO: UMA APROXIMAÇÃO ENTRE A TEORIA DO ATOR-REDE (ANT) E FOUCAULT
}

Este artigo e as reflexões que o embasam têm origem no cruzamento de dois campos de pesquisa independentes - mercado informal e segurança pública -, cujas questões empíricas nos suscitaram inquietações semelhantes que permitiam estabelecer pontos de comunicação entre as formulações de Michel Foucault sobre poder e governamentalidade e a teoria do ator-rede (ou ANT - actornetwork theory). Essa comunicação, porém, nem sempre é direta e passa pela construção de mediações teóricas, conceituais ou tecnológicas. Nesse sentido, as relações entre a formalização da atividade de vendedores ambulantes pelos órgãos municipais de ordenamento e o tempo de atendimento de ocorrências policiais em um centro integrado de comando e controle são traçadas aqui a partir dos "procedimentos de inscrição". Por meio da noção de "inscrição" procuramos articular temas de pesquisas que costumam ser trabalhados separadamente. Tais "procedimentos de inscrição" criam parâmetros que permitem ordenar, por um lado, diferentes atividades comerciais em uma única inscrição municipal (que constitui sua "formalização") e, por outro, a grande variedade de ocorrências policiais (sobrepostas a esquema de medição de tempo) de modo que se tornem comparáveis e classificáveis segundo critérios objetivos. Nosso argumento é que nos dois casos as inscrições assim produzidas compõem um mesmo procedimento de ordenação do espaço urbano, em constante processo de construção.

Assim, ressaltamos a centralidade dos "procedimentos de inscrição" no estabelecimento de relações de poder, o que, em nome do ordenamento urbano, 
permite pôr em funcionamento programas de gestão de populações e de territórios da cidade do Rio de Janeiro. O primeiro desses programas foi pensado no âmbito da Secretaria Municipal de Ordem Pública (Seop) visando formalizar o comércio nas ruas do Rio de Janeiro, mediante um cadastro que distribui licenças aos vendedores, antes considerados informais. O Cadastro Único dos Ambulantes (Cuca) é procedimento de ordenamento urbano que atua via formalização com o objetivo de fixar, por investimento de formas (Thévenot, I986), arranjos socioeconômicos que são sempre múltiplos e heterogêneos. Nesse sentido, trata-se de uma convenção que busca tornar estável um movimento reticular de circulação mercantil e passível de ser transportado para outros lugares. Quando se cria um cadastro do comércio informal - que consiste na elaboração de um formulário de formalização -, há todo um investimento de classificação, de codificação, de normalização que torna possível uma inscrição - que então pode ser transportada e utilizada de maneira comparativa, construindo formas de equivalência entre coisas que antes eram consideradas diferentes. Ao mesmo tempo, a formalização estabelece clivagens entre, de um lado, aqueles que são equivalentes, aqueles que são comparáveis, aqueles que são fixos e, de outro, os inclassificáveis, não codificáveis, não normais - chamados, no caso, de "informais".

O segundo caso estudado diz respeito ao atendimento de chamadas e ocorrências policiais no Rio de Janeiro, realizado no Centro Integrado de Comando e Controle (CICC) - cujo prédio é gerido pela Secretaria de Segurança do Estado (Seseg) -, principalmente por meio de um software que interconecta agentes nas áreas da região metropolitana da capital do estado. Com base na medição e na comparação dos tempos de atendimento e sua evolução, são estabelecidas metas de eficiência e racionalidades governamentais, que servirão, entre outras coisas, para justificar o alto investimento financeiro necessário para a construção do CICC e seu funcionamento diário.

Portanto, tendo como pano de fundo nossas pesquisas, o artigo parte da relação que Foucault constrói entre poder e saber para identificar possíveis continuidades entre sua reflexão sobre governamentalidade e formulações centrais da ANT. Em seguida desenvolvemos aspectos específicos da relação entre poder e saber que interessam aos objetivos de aproximação aqui propostos - sua dimensão estratégica, as positivações e os seus efeitos. Analisamos então a ideia de "inscrição" (Latour \& Woolgar, I997), relacionando-a aos conceitos de "tradução" (Callon, I986) e de "controle a longa distância" (Law, I986). Para tanto, recorremos a textos seminais dos três autores que, entre o final dos anos I970 e a primeira metade da década de i980, elaboraram e reuniram os principais elementos constitutivos da ANT: Michel Callon, Bruno Latour e John Law. É preciso ressaltar que, ao apontar conexões teóricas entre Foucault e a ANT a partir do conceito de "inscrição", não pretendemos esgotar as convergências e divergências entre os autores, tampouco estamos afirmando que es- 
se seja o único (ou mesmo o principal) ponto de interlocução entre eles. Esse cruzamento entre esses autores nos interessa especificamente por permitir pensar, ainda que de forma interessada e parcial, problemas de pesquisa que nos parecem comuns. Isso posto, apresentamos, enfim, o funcionamento dos dois procedimentos de "inscrição" que pesquisamos, o Cuca e o Tide, ${ }^{\mathrm{I}}$ para mostrar os seus efeitos no processo, sempre instável e conflitivo, de gestão da ordem pública.

\section{PODER, SABER E PONTOS DE APOIO RECÍPROCOS}

Foram as considerações acerca das relações entre saber e poder desenvolvidas por Foucault ao longo de sua obra que fizeram convergir inicialmente as pesquisas que vínhamos realizando de forma separada. Poder e saber são dimensões relacionais cuja separação binomial serve para efeitos meramente analíticos, ou seja, Foucault (I999) lida, sobretudo, com as mediações, interfaces e pontos de apoio recíproco entre essas dimensões. Em vez de questionar quais seriam os "condicionantes da produção política dos saberes" ou as "possibilidades de desvelamento do poder", ele buscou refletir sobre a relação intricada dessas dimensões, conduzindo-nos a questões completamente novas acerca das "lutas em torno da verdade e seus efeitos". Tais lutas não têm para o autor um sentido unívoco, de modo que é importante dar atenção aos pontos de emergência e proveniência (Foucault, I979) da construção de determinado problema ou do entendimento das formas de problematização (Foucault, I997). Seguindo as relações entre poder e saber e seus pontos de bifurcação, ele constrói em um só movimento a possibilidade de pensar planos de referências comuns a elementos heterogêneos para a produção da verdade e de seus regimes específicos.

Seguindo tal perspectiva, em entrevista a Alexandre Fontana, Foucault (I979: I2) afirma:

A verdade é deste mundo; ela é produzida nele graças a múltiplas coerções e nele produz efeitos regulamentados de poder. Cada sociedade tem seu regime de verdade, sua política geral de verdade: isto é, os tipos de discurso que ela acolhe e faz funcionar como verdadeiros; os mecanismos e as instâncias que permitem distinguir os enunciados verdadeiros dos falsos, a maneira como se sancionam uns e outros; as técnicas e os procedimentos que são valorizados para a obtenção da verdade; o estatuto daqueles que têm o encargo de dizer o que funciona como verdadeiro (grifos nossos).

Uma das características da interface entre poder e saber do mundo ocidental é a centralidade da ciência, cujos procedimentos fazem distinguir os enunciados verdadeiros daqueles falsos. A atenção que Foucault dá a esses procedimentos é o que diferencia sua abordagem das que procuram as exterioridades políticas capazes de explicar os fatos científicos ou, por outro lado, a interioridade científica que possa iluminar uma verdade livre da influência do poder. Os regimes de verdade são construídos exatamente na interface entre poderes e saberes, entre o "exterior" e o "interior" dos procedimentos científicos. 
Segundo Desrosières (I993), a sociologia e a história das ciências sempre oscilaram entre perspectivas internalistas e externalistas. Como exemplos da primeira, podemos citar a história do desenvolvimento do conhecimento, com seus teoremas, demonstrações e resultados, normalmente feita por físicos e matemáticos. Na perspectiva externalista, temos a história das condições sociais que tornaram possível esse desenvolvimento, seus equipamentos, seus laboratórios e suas relações com a economia e com o Estado, a cargo de sociólogos e historiadores (Shapin, 20I4). De acordo com Desrosières (I993), essas duas maneiras de estudar a ciência pouco se entrecruzaram, ainda que possamos facilmente imaginar pontos de apoio recíprocos para a conformação de ambas as linhas de pesquisa.

A partir dos anos I970 a divisão entre os internalistas e externalistas começa a ser questionada, primeiramente por Bloor (2008), em seguida por Hughes (I983; I986), Latour (20 I I) e Callon (I998b). Nessa perspectiva renovadora, assim como para Foucault, é fundamental entender o conjunto de operações práticas dos cientistas (seus procedimentos). Esses procedimentos agregam em um só plano, feito de múltiplas conexões, aquilo que permanecia separado na divisão entre internalistas e externalistas, assim como os âmbitos até então apartados da economia, da política e do conhecimento científico. ${ }^{2}$

Entretanto, não é apenas no estudo da ciência que o foco nos procedimentos práticos revela importantes aspectos da interface entre saber e poder. $O$ trabalho de Foucault e o da ANT enfatizam a conexão em redes, ${ }^{3}$ de diversos elementos e atores - heterogêneos - em que deixa de fazer sentido a distinção entre internos e externos. A costura desses elementos e atores seria, simultaneamente, resultado e efeito das relações de poder em funcionamento - o tamanho e a estabilidade das redes propiciariam possibilidades de exercício do poder mais amplas e previsíveis. Daí que para se entender o funcionamento dos dispositivos de saber-poder seja necessário compreender também o modo como elementos e atores são reunidos e passam a operar por meio de procedimentos práticos, dirigidos a determinados objetivos, segundo racionalidade específica, produzindo formas particulares de saber e delas se retroalimentando. A partir disso, podemos então afirmar que este artigo trata dos procedimentos de funcionamento de duas "tecnologias de governo".

A formalização da atividade dos vendedores ambulantes no Rio de Janeiro não poderia ser realizada sem a conexão entre instituições de representação dos interesses do microempresariado, da construção de ordem pública, das associações dos ambulantes, dos técnicos em programação e dos funcionários que elaboraram os cadastros. As conexões entre cada um desses elos permitiram a implementação de um sistema de identificação capaz de atuar em toda a cidade. Seria imprecisa a linha divisória que se tentasse estabelecer entre Estado e sociedade ou entre a política, a técnica e a economia na constituição desse processo. Foram esses pontos de apoio recíprocos que possibilita- 
ram a estruturação do Cuca, assim como a do CICC-RJ demandou coordenação entre órgãos das esferas federal, estadual e municipal, diferentes secretarias de governo, muitas empresas de tecnologia de comunicação e segurança, vários objetos e dispositivos informáticos, pessoas de diversas origens e filiações institucionais ou empresarial, redes de eletricidade e transmissão de dados etc. O próprio Estado é pensado como uma realidade compósita (Foucault, 2004; Callon \& Latour, I98I) que incluiria todos esses elementos e cuja existência vincula-se a sua atividade prática governamentalizada, sendo o CICC caso exemplar dessa concepção. A heterogeneidade dos participantes dessa rede constitutiva do Estado e a própria concepção do Estado como uma rede heterogênea já fazem com que sua oposição em relação à sociedade (civil) perca muito do sentido e da operacionalidade.

A construção de redes se dá, então, por meio de diversas estratégias para obrigar ou convencer os atores envolvidos a cooperar, o que pode demandar os mais diversos métodos e formas de compor alianças ou percepções de interesses coletivos. Nesse sentido, o termo "tradução", tal como foi definido e pensado pela ANT, ${ }^{4}$ é especialmente útil:

No processo, acontece aquilo a que Callon e Latour se referem como "tradução", na qual o ator ou força é capaz de exigir ou contar com um modo particular de pensamento e de ação de outras pessoas, daí aglomerá-las em uma rede não devido a laços ou dependências legais ou institucionais, mas porque elas chegaram a compreender seus problemas de maneiras pactuais e os próprios destinos como estando, de alguma maneira, ligados uns aos outros. Daí, pessoas, organizações, entidades e áreas que permanecem diferenciadas pelo espaço, pelo tempo e pelas fronteiras formais podem ser colocadas em um alinhamento frouxo, aproximativo e sempre móvel e indeterminado (Miller \& Rose, 20I2: 48-49).

Voltaremos a tratar da tradução mais adiante, destacando agora a dimensão estratégica do saber e do poder.

\section{CONSTRUINDO HETEROGENEIDADES}

O rompimento com o binômio internalista/externalista na equação poder/saber e a valorização das controvérsias ou problematizações ao revés das continuidades unívocas mostraram-se pontos relevantes de aproximação entre Foucault e os autores da ANT. Esse duplo movimento fundamenta a possibilidade, aberta pelo primeiro e desenvolvida pelos últimos, de pensar heterogeneidades em articulação e disputa, bem como relações entre objetos e domínios que se encontravam antes solidamente separados. O duplo movimento coloca no centro da análise os pontos de apoio recíprocos e não as relações de dominação entre o que se considera conhecimento científico, pertencente ao mundo social, e o mundo político-econômico. Essa dinâmica ganha sentido quando levamos em conta a dimensão estratégica do procedimento genealógico foucaultiano, a analítica de seus efeitos e suas positivações. 
Ao avaliar seus primeiros anos de docência no Collège de France, Foucault (I999) revela o plano de construção do que chamou de genealogia, "a constituição de um saber histórico das lutas e a utilização desse saber nas táticas atuais". Sua reflexão é simultaneamente política, evocando as mobilizações desde I968, e analítica, ponderando as possibilidades de uso dos saberes "vencidos" na contraposição à narrativa histórica oficial. Para que, entretanto, essa memória das lutas não seja um ajuste ou retorno ao cânone que pretenderia "filtrá-las, hierarquizá-las e ordená-las", e porque são "insurreições dos saberes assujeitados", o significado político e analítico do procedimento genealógico não poderia pretender apenas conferir droit de cité a esses saberes sem os posicionar frente ao estabelecido, interrogando as estratégias de poder. A genealogia não pretende "integrar o outro", mas sim extrair sua potencialidade crítica - oriunda de sua perspectiva em um embate.

Não é fortuito, assim, que Foucault proponha a inversão da clássica proposição de Clausewitz (I955), segundo a qual a guerra seria a continuação da política por outros meios, caracterizando o poder como a guerra continuada por outros meios. As relações entre poder e saber são atravessadas, na análise foucaultiana, por todo um vocabulário da guerra, começando pela perspectiva estratégica, porque, afinal, são as relações de força que as organizam. A análise foucaultiana, portanto, pressupõe uma grade de legibilidade da guerra (Foucault, I999).

Seu objeto de estudo naquele momento, a prisão, é visto em meio a um conjunto de táticas como catalisador das estratégias, mais do que como resultado de uma ação institucional, função ou estrutura. Ao posicionar a dimensão estratégica no centro do procedimento genealógico, Foucault inaugura uma analítica da penalidade, que só pode ser compreendida no interior de uma analítica do poder, e não como uma teoria do poder, que ele sempre se recusou a sistematizar, apesar das "cobranças" que lhe faziam. A identificação do poder como objeto teórico pressupõe a existência de algo como um "ser" do poder, bem como a descrição de sua estrutura, suas regras e seu funcionamento (Foucault, I999). A analítica do poder, ao contrário, não se propõe a definir o que o poder "é" nem o toma por objeto, mas percebe situações estratégicas nas quais o que se chama de poder é necessariamente pensado como um efeito das relações. $O$ poder não seria uma coisa, instituição, função, estrutura, tampouco um dote ou uma propriedade. Menos ainda se pode dizer que ele atua simplesmente excluindo ou reprimindo. Situação estratégica complexa (Fonseca, 2002), o poder é - e Foucault insiste especialmente nesse ponto - um efeito e não uma causa.

Concepção bastante semelhante de poder é desenvolvida pela ANT, desde seus primeiros textos. As relações de poder são pensadas como efeito da estabilização de redes, que formariam um agregado cada vez maior de aliados heterogêneos. Nessa chave, buscou-se compreender tanto o êxito da expansão marítima portuguesa nos séculos XV e XVI (Law, 20I2) e de Pasteur com a teoria 
microbiana no final do século XIX (Latour, 200I) quanto o fracasso das primeiras tentativas de reprodução de vieiras em cativeiro na baía de Saint-Brieuc (Callon, I986), do desenvolvimento dos veículos elétricos pela estatal francesa de energia (Callon, I998b) ou de um avião de caça pela Royal Air Force britânica (Law, 2002).

Ao entender o poder como efeito de um conjunto de variadas e exitosas estratégias para envolver os outros mais do que como uma causa desse êxito, Latour (I986) está em consonância com a abordagem foucaultiana, principalmente, da disciplina e do dispositivo de sexualidade (Foucault, 2003; I985). As aproximações, entretanto, se aprofundam se tomarmos também a discussão sobre a governamentalidade e o poder como a capacidade de "conduzir as condutas" (Foucault, 2004; 2008). Ao apresentar o "problema do poder" na sociologia, Law (I998: 63) parte da pergunta: "como atores e coletividades tentam conseguir a submissão de agentes e objetos naturais que poderiam resistir a essa tentativa?". Em cada caso específico, ele afirma, são postos em funcionamento diferentes técnicas de poder, que seriam os métodos pelos quais os atores buscam tornar mais regular e previsível o comportamento de outros atores, abrindo certas possibilidades de ação e rechaçando outras. Tal concepção ignora diferenças de escala, já que o mecanismo de poder formado por essas técnicas, seria capaz de explicar tanto o funcionamento do Estado quanto de um pequeno laboratório de químicos pesquisando um remédio contra arritmia cardíaca. E, mais importante, explicaria tanto os efeitos que tornam possível a construção e estabilização das redes heterogêneas quanto os efeitos de poder decorrentes disso. Seja qual for a escala da rede que se pretende analisar, o mecanismo utilizado é a descrição etnográfica minuciosa de seus funcionamento, atores e conexões. Com isso, voltamos à questão da importância da análise dos procedimentos práticos que permitem a construção, a estabilização e o funcionamento da rede. Como se vê, tanto para Foucault quanto para os autores da ANT, a descrição detalhada dos mecanismos infinitesimais de operação do poder em sua microfísica (Foucault, 2003) - ou o desdobrar sem fim das redes, no intuito de traçar sua cartografia (Latour, 20I2) - é a tarefa que mais interessa na pesquisa.

\section{PRISÃO, EXAME E ESTATíSTICAS}

Com o tratamento analítico das estratégias e seus efeitos, Foucault pretende distanciar-se das abordagens correntes do poder, que privilegiam seus aspectos "repressivos" e "excludentes" - o que chamava de "hipótese repressiva" - em prol de suas positivações. A prisão (Foucault, 2003), por exemplo, revela mecanismos muito mais complexos e profundos do que a exclusão: ela integra, projeta, purifica e recicla estratégias de poder, além de redistribuir fluxos de populações inteiras, dando forma e organizando aqueles denominados delinquentes. A analítica estratégica dos efeitos de poder permite observar que sua forma de ação não vai apenas buscar "eliminar os indesejáveis" ou "banir os contestadores". Dizer que a prisão não só isola, mas faz circular o poder, significa centrar a análise em 
seus mecanismos mais sutis e complexos, aqueles que positivam e produzem indivíduos, assujeitamentos, subordinações, ou seja, que dão forma e não simplesmente negativam e interditam.

Assim, a análise de Foucault pensa a articulação entre técnicas de exclusão e inclusão. A transformação que é operada na exclusão do louco ou do criminoso vai de par e passo com sua clausura, ou seja, a transformação é também condição de possibilidade de sua exclusão. No interior da prisão ou do hospital, lugares considerados emblemáticos da exclusão (do criminoso ou do louco), encontra-se em prática toda uma série de saberes e poderes que objetivam seu alvo, constituindo-os e reconstituindo-os como sujeitos.

O que Foucault chama de exame se situa nesses pontos de conexão entre saberes e poderes que articulam uma analítica estratégica de suas formas de positivação e seus efeitos. Nessas práticas de exame, simultâneas à busca de compreensão dos indivíduos, ocorre a produção destes últimos. Quando Foucault diz que o indivíduo é um efeito positivado de certas estratégias de poder, está indicando que ele não é uma matéria previamente existente, que seria sufocada, destruída, submetida e descaracterizada pelo poder (repressivo), mas sim o efeito de relações de poder/saber que procuram inscrevê-lo produtivamente.

O exame se apoia no recurso às técnicas de notação, na organização de arquivos, na sistematização de dossiês, ou seja, nas diversas formas documentais de inscrição de informações sobre os indivíduos. ${ }^{5}$ Por meio da noção de caso, diferencia-se cada um desses recursos, individualizam-se as situações, examinam-se minuciosamente os detalhes. No exame há uma passagem de mão dupla, partindo do professor, médico ou instrutor militar - que buscam objetivar nos indivíduos seus conhecimentos - e também do aluno, paciente ou cadete - que informam os primeiros sobre suas aptidões, habilidades e capacidades. $O$ que permite essas passagens é a inscrição desses indivíduos em uma organização via classificação e qualificação que os individualizam minuciosamente e lhes esquadrinham os corpos no tempo e no espaço em um regime de notações que descreve, mensura e compara cada caso particular com os outros.

Em articulação com o exame, a construção dos registros estatísticos leva em conta as flutuações populacionais, em convergência também estratégica, positivada e expressa em termos de seus efeitos. A própria população é um efeito produtivo de uma estratégia de objetivação de outro nível (ou regime) de verdade (Foucault, 2004). Sua coerência interna, suas regularidades e propensões não são descobertas ou medidas, como alerta Desrosières (I993), mas sim o produto de uma série de "convenções de equivalência", para usar sua fórmula que se apoia em escritos da ANT e da economia das convenções. Só passando por esses procedimentos de inscrição é possível utilizar a estatística como ferramenta de entendimento das dinâmicas populacionais.

Isso significa que a população e as estatísticas são, inseparavelmente, construções sociotécnicas; não existem de forma previamente mensurável. 
Para algo ser quantificado (e não apenas medido como supõem as metrologias realistas), as convenções de equivalência exigem comparações, negociações, compromissos, codificações, procedimentos de replicação e cálculo. A mensuração passa pelas convenções, e a medida nada mais é senão a operacionalização controlada dessas convenções (Desrosières, I993). Nessa direção apontada por Desrosières e explicitamente apoiada em um vínculo entre Foucault e a ANT, os procedimentos estáveis e transportáveis da média, probabilidade, correlação ou regressão foram produzidos por muitas formas de problematização ou de controvérsias, que inscrevem a população como objeto identificável.

O exame e a estatística evidenciam as três dimensões (estratégia, positivação e efeitos) que aqui desdobramos e sua conexão com os procedimentos de inscrição. São eles que permitem que o exame e a estatística possam funcionar no entendimento de condutas individuais ou coletivas, e são as "inscrições" que iluminam os jogos de poder/saber envolvidos em sua construção (do exame e também das estatísticas), permitindo-nos pensá-los como estratégias e por meio das positivações e dos seus efeitos. Foucault utiliza o conceito de normalização para indicar a maneira pela qual poder e saber se apoiam reciprocamente nas técnicas do exame e da estatística, distinguindo, porém, a normalização disciplinar, comumente associada ao exame, da normalização securitária com que operam as estatísticas (Foucault, 2004). Embora não caiba nos limites deste artigo uma discussão mais pormenorizada sobre a normalização, vale notar que, para que exame e estatística sejam operantes, é necessária sua inscrição, que em cada caso é feita de maneira distinta. ${ }^{6}$ A seguir procuraremos circunscrever o que é, afinal, "inscrição" a partir dos principais conceitos da ANT.

\section{DESDOBRANDO A INSCRIÇÃO}

Como já visto, "tradução" é um dos conceitos-chave da ANT, tendo sido inicialmente elaborado por Callon (I979), ainda no final da década de I970, na mesma época em que Latour apresentava, em seu primeiro livro com Woolgar (I 997), o conceito de "inscrição". Latour (20I2) identifica em três textos fundamentais o início da ANT, por terem inserido efetivamente os não humanos na teoria social. São eles o seu próprio livro, de I984, sobre o pastorismo e os micróbios (Latour, 200I), e os artigos de Callon (I986) e Law (I986) publicados em coletânea organizada por este último. Esses artigos abordam uma tentativa por parte de cientistas de criar fazendas de vieiras numa baía ao norte da França por meio de técnicas provenientes de biólogos japoneses e o caso histórico da Carreira das Índias, grande expedição mercantil e militar realizada todos os anos por uma frota portuguesa circundando o continente africano em direção a Calicute. Independentemente da cronologia dos textos e termos, da autoria inicial desses conceitos ou de quando se deu efetivamente uma ruptura perceptível a ponto de identificar uma nova corrente teórica, os três autores em questão trabalha- 
ram e pensaram coletivamente na primeira metade da década de I980-como pode ser acompanhado pelos diferentes artigos que publicaram em duplas e pelas múltiplas remissões às obras uns dos outros. Alguns problemas teóricos e metodológicos trazidos pelo campo de estudos da sociologia da ciência e da tecnologia foram analisados, questionados e experimentados pelos três, levando a soluções bastante próximas e coerentes nos trabalhos que desenvolviam paralelamente e em colaboração. E, como argumentamos, o uso de conceitos - ou do método - de Foucault é fundamental para as soluções encontradas, para as perguntas realizadas e para os caminhos seguidos pela ANT.

A articulação dos conceitos de "inscrição" e "tradução" é um bom exemplo disso. As etnografias em laboratórios científicos, por exemplo, explicitam a centralidade dos processos de inscrição na produção da ciência - mais ainda, são absolutamente fundamentais para a efetivação e o funcionamento das relações de poder nas quais o conhecimento e os instrumentos científicos estão envolvidos. Em outras palavras, explicam por que a ciência, de forma geral, "é tão poderosa". Não se trata de um poder que seria sua propriedade ou que emanasse dela, mas de um poder que, para ser exercido, precisa necessariamente se apoiar na ciência, como um ponto de passagem obrigatório’ para constituir uma rede sólida de atores heterogêneos - ou um dispositivo. ${ }^{8} \mathrm{~A}$ estabilidade da rede, obtida por meio de um conjunto de estratégias, táticas e técnicas, tem por efeito, e não causa, relações de poder. Nesse panorama, a inscrição científica - ou o traço - é tão importante porque possibilita que eventos produzidos e observados localmente, e por tempo limitado, em laboratórios de qualquer parte do mundo ganhem estabilidade (tornando-se duráveis), mobilidade e sejam tratados em outros lugares (medidos, comparados, manipulados a fim de esmiuçar resultados). Com isso, podem circular pelos diversos pontos locais que formam a rede científica - composta por textos, máquinas, laboratórios e pessoal treinado, ou corpos docilizados -, propiciando a transposição de uma escala local e micro para uma escala macro, ampliada, possivelmente global (Law, I998). Um dos principais efeitos de poder decorrentes é o controle a distância (Law, I986).

As inscrições são a tradução de heterogeneidades e eventos em cifras, diagramas ou textos diretamente utilizáveis e que, supõe-se, guardam relação direta com o que é traduzido. Sua produção se dá a partir de tecnologias de inscrição, em aparatos chamados de "inscritores" (Latour \& Woolgar, I997). Inscritores e inscrições fazem com que acontecimentos possam ser móveis, comparáveis, duráveis e tratáveis, convertendo essas heterogeneidades em homogeneidades (Law, I998). As possibilidades que disso decorrem têm importantes implicações para o funcionamento prático das relações de poder e para sua estabilização a partir da rede heterogênea que constitui o Estado e seus aparatos de governo, como veremos adiante na exposição de nossas pesquisas empíricas.

A convergência da ANT e uma "sociologia foucaultiana" é proposta também por Miller e Rose (2012) por meio do conceito de "governo a distância". Os 
autores ressaltam a afinidade complementar entre, por um lado, a noção de "governamentalidade" e seus mecanismos e meios indiretos de "dispor as coisas" e de regular a conduta dos indivíduos que compõem uma população (Foucault, 2004; 2008) e, por outro, o conceito de "ação a distância"9 (Latour, 20 I 2), uma sistematização generalizante do "controle a distância", pensado por Law (I986). Tomando como principal método de pesquisa o "desdobramento" da ação, mediante uma cartografia dos atores nela envolvidos (humanos e não humanos, das mais diversas "figurações" ${ }^{10}$ ), a ANT leva ao extremo a ideia, bastante cara a Foucault, de voltar a atenção mais para os mecanismos das relações de poder do que para suas causas. O “como", em vez do "por que”, é a principal pergunta (Dean, I999). Reiterando, o poder seria um efeito ou, melhor, a ação - a distância - seria um efeito da composição de uma rede de elementos heterogêneos.

O método da descrição etnográfica exaustiva com o qual a ANT se propõe a desdobrar a ação e a enfatizar os mecanismos práticos de seu funcionamento permitiu que algumas das considerações foucaultianas fossem desenvolvidas a partir de pesquisas de campo. Nos estudos de laboratório, inicialmente, descreveram-se a rede de elementos composta e as etapas necessárias para a criação dos traços, gráficos e números que vão preencher artigos científicos, servir para outros pesquisadores e colaborar com o "desenvolvimento" da ciência. Em suma, a etnografia dos procedimentos de inscrição e da ação dos inscritores permitiu desdobrar alguns dos mecanismos não apenas da ação a distância, mas também do exercício de relações de poder pela ciência.

Miller e Rose (20I2: 44) chamam a atenção para razões que tornam os procedimentos de inscrição centrais para o governo e, mais especificamente, para a governamentalidade neoliberal:

"Conhecer" um objeto de tal maneira que ele possa ser governado é mais do que
uma atividade puramente especulativa: exige a invenção de procedimentos de
notação, modos de coletar e de apresentar estatísticas, o transporte delas para
centros onde se possam fazer cálculos e avaliações, e assim por diante. Median-
te tais procedimentos de inscrição é que se formam os diversos domínios da
"governamentalidade", "objetos" tais como a economia, a empresa, o campo social
e a família são transformados em uma forma conceitual particular e permeabi-
lizados para a intervenção e o controle.

Ao enumerar as características do neoliberalismo, Foucault (2008) atenta para a aplicação da grade de inteligibilidade da economia sobre um número cada vez maior de domínios, como forma de definição de objetivos, estruturação das atividades e avaliação de resultados. As noções de eficiência e eficácia, por exemplo, passam a balizar decisões e horizontes de ação, bem como a pautar o uso e desenvolvimento de "tecnologias de governo". Ganha relevância o conhecimento oriundo da administração de empresas, que orienta a ação na esfera da administração pública e das instituições estatais, a partir de noção de eficiência baseada majoritariamente em inscrições e metrologia econômicas. 
Vale destacar novamente a centralidade dos "inscritores" na constante medição e comparação de diversos resultados e atividades, ao criar objetivos palpáveis e formas de os atingir que podem ser organizadas em metas. Como mostraremos no exemplo a seguir, relativo à pesquisa no CICC, os dispositivos de inscrição que fazem parte do próprio sistema de comando e controle constituem uma série de variáveis que passam não apenas a ter existência concreta como a ser levadas em conta na busca incessante de maior eficácia. E a concepção de eficácia em questão considera exclusivamente metrologias econômicas, que nem sempre se coadunam com o efeito ou os resultados esperados por aqueles que trabalham no sistema ou que deles são alvos ou beneficiários. As metas atingidas, entretanto, podem ser apresentadas pelos gestores como provas incontestáveis dos resultados positivos obtidos a partir do uso do sistema ou das estratégias gerenciais ou de organização adotadas.

\section{MARÉ ZERO E TIDE: TRADUZINDO A AÇÃO EM TEMPO}

Com a inauguração do CICC em maio de 20I3, alguns serviços operados pelo governo do Estado do Rio de Janeiro foram transferidos, integral ou parcialmente, para seu prédio. Entre eles estavam o atendimento de chamadas da hotline da Polícia Militar (I90) e o despacho de viaturas para os locais das ocorrências, serviço que é internamente conhecido como Maré Zero. ${ }^{11} \mathrm{~A}$ integração operacional entre os dois serviços dependia de uma rede de elementos heterogêneos que deveria funcionar de modo a possibilitar a comunicação entre os mais diversos pontos da região metropolitana do Rio de Janeiro e o CICC, e entre os dois setores ( 90 e despacho) localizados no mesmo andar do prédio. Poderíamos classificálos como fluxos "fora-dentro", "interno" e "dentro-fora". O primeiro fluxo opera a ligação entre o exterior e o CICC por meio da rede telefônica - chamadas para o sistema de emergência da PM - de "solicitantes" e atendentes de I9o, e do software que territorializa e distribui as chamadas em uma plataforma cartográfica da região metropolitana do Rio de Janeiro, chamado de Teleatendimento Integrado de Demandas Emergenciais (Tide). Quando as chamadas são inseridas no sistema elas se tornam "ocorrências", e passam a ser tratadas pelos despachadores - policiais militares lotados na Maré Zero.

O fluxo interno é organizado principalmente a partir de duas estratégias. A primeira delas é a distribuição espacial dos despachadores. Cada policial ocupa uma cadeira diante de duas telas de computador, referentes às áreas de atuação de dois batalhões da PM nas quais se concentra seu trabalho. A segunda estratégia é viabilizada pelo Tide, que integra as informações recebidas por telefone e inseridas no sistema pelos atendentes de I9o num mapa da área do batalhão (fornecido pela plataforma Google Maps), que constitui a interface do software à qual os despachadores têm acesso. Por meio de bandeiras coloridas (verdes ou vermelhas), que marcam os locais com ocorrências sendo atendidas ou à espera de atendimento, e de ícones que indicam o posicionamento de 
cada viatura policial disponível naquele batalhão, o software fornece elementos visuais que tornam sua operacionalização facilmente compreensível ao observador e aparentemente intuitiva para os despachadores.

Ao associar uma viatura a uma ocorrência, por meio de dois ou três cliques com o mouse integrado à tela, os despachadores iniciam o terceiro fluxo, "dentro-fora". As informações inseridas no sistema - tanto a descrição da ocorrência quanto a geolocalização e indicações sobre trajeto mais rápido a ser utilizado - aparecem nas viaturas por meio de um computador embarcado chamado Conecta, no qual outro ambiente do Tide é acessado. O pacote formado por Tide e Conecta constitui a "solução integradora" fornecida pela empresa Geocontrol. Além disso, os despachadores também podem estabelecer contato com os policiais nas viaturas por meio dos rádios da PM, para melhor explicar determinadas informações. Mediante esses contatos e o preenchimento de informações sobre a ocorrência no Conecta, os policiais nas ruas também estabelecem outro fluxo "fora-dentro", contudo bastante diferente daquele iniciado com a chamada para o I90.

Entre o momento em que chega a chamada telefônica e suas informações começam a ser inseridas no Tide pelos atendentes do I 90 e o encerramento da "ocorrência", uma grande quantidade de inscrições é produzida, passando a alimentar o banco de dados do próprio CICC e da Seseg. ${ }^{\mathrm{I2}}$ Essas inscrições são de tipo variado e podem ser relativas à classificação das ocorrências, à distribuição de ocorrências por áreas, a informações sobre suspeitos ou indivíduosalvo de denúncias, etc. Para a discussão que realizamos, entretanto, nos concentraremos nas inscrições referentes às medições de tempo e no modo como são transformadas em índices de eficiência ou metas a cumprir.

Nosso foco incidirá em dois recortes feitos nesses fluxos, geradores de dois tipos de inscrição, que servem diferentemente ao propósito da busca de eficiência na ação. Denominados "tempo de despacho" (td) e "tempo de atendimento" (ta), o primeiro compreende o tempo decorrido desde o recebimento da chamada até o envio da viatura - logo, se encerra ao iniciar o fluxo dentro-fora -, e o segundo se estende até o encerramento da ocorrência, ou seja, até que uma informação específica do fluxo fora-dentro marque o final do evento nomeado "ocorrência". Sobre o tempo de despacho, o trabalho se dava a partir de metas.

Exigências de redução constante de tempo médio - em reuniões comandadas por oficiais da PM e relatadas pelos despachadores como tratando monotematicamente desse assunto - eram parte da rotina operacional da Maré Zero desde o início do funcionamento do CICC. Por conta do controle realizado, dos turnos de trabalho na PM e do sistema de senhas para operar o sistema, a identificação de cada despachador e de seu tempo médio, torna possível a comparação e possivelmente a competição entre eles, fazendo com que se lograsse obter, nos três anos de funcionamento do centro, considerável redução do tempo médio de despacho. 
Em visita de campo realizada no final de novembro de 2013 , quando o tempo médio de despacho se aproximava de oito minutos, um sargento declarou:

Muita coisa que está funcionando já aqui se deve à pressão pelas boas estatísticas. A pressão sobre a gente só vem crescendo para que o atendimento seja cada vez mais rápido. Antes a gente tinha dez minutos para despachar, aí passaram para cinco, que é muito difícil, e o último informe é que quando chegar em cinco vão dizer que a gente devia despachar em dois minutos. Aí fica bem para o comandante, né?

Em aproximadamente seis meses de uso do Tide e do CICC, o tempo médio de despacho, que era superior a dez minutos quando o sistema começou a operar, já havia sido reduzido em mais de dois minutos. Podemos associar essa redução tanto à pressão exercida pelos superiores quanto à maior destreza dos despachadores em manejar o Tide, com seus caminhos, erros e formas de burlá los. Em visita realizada em março de 2016 , a redução no tempo médio de despacho era ainda mais significativa, já que este estava na casa dos quatro minutos, tendo superado a meta que, dois anos e quatro meses antes havia sido considerada "muito difícil". Perguntado sobre qual seria a nova meta, o coordenador do setor respondeu: "O objetivo é ir sempre baixando. Baixa um pouco, a gente quer que baixe mais. E por aí vai”. A redução do tempo do despacho foi apresentada, nas palavras do coordenador, como sendo "uma amostra de como isso aqui funciona mesmo, mesmo com os problemas".

No "tempo de atendimento", a relação entre tempo médio e eficácia não pode ser apresentada da mesma forma pelo discurso dos gestores do sistema, que buscam outras formas de convencer o interlocutor sobre os efeitos positivos do funcionamento do CICC de modo geral. Isso se deve à própria variedade de situações incluídas na categoria que origina o atendimento, a "ocorrência", que pode ter graus de complexidade diversos e requerer mobilização de agências, instituições e recursos diferentes a cada caso. Nessa mesma visita de março de 20I6, o coordenador da Maré Zero deu o exemplo do impacto do CICC no "tempo de atendimento", a partir das inscrições que estavam sendo transmitidas no grande videowall, em destaque por conta do tamanho e da posição central. Nele víamos um quadro com duas listas em que inscrições (uma dúzia em cada lista, em amarelo ou vermelho) marcavam tempos de atendimento (ta) ou tempos de despacho $(t d)$ associados a determinadas "ocorrências". As inscrições em amarelo indicavam chamadas classificadas como urgentes e cujo despacho ainda não havia sido realizado, por ordem decrescente de td, e aquelas em vermelho marcavam ocorrências não finalizadas, por ordem decrescente de ta. A lista em amarelo continha apenas uma pequena parcela das chamadas, justamente aquelas consideradas prioritárias e que, por isso, costumam ter td bastante reduzido, enquanto as inscrições em vermelho abarcavam todo o universo de ocorrências em atendimento, classificadas apenas em função de seu ta.

No topo da lista em vermelho aparecia uma ocorrência que totalizava já mais de oito horas e 40 minutos, enquanto a última delas havia acabado de ultra- 
passar a primeira hora. A heterogeneidade das ocorrências com as quais a PM lida justificaria a grande amplitude observada entre os diferentes ta, e impediria a realização do mesmo tipo de medição, de comparação e de metas do td. Como explicou o coordenador, a ocorrência que aparecia em primeiro lugar na lista em vermelho envolvia a prisão de milicianos, e deveria arrastarse ainda por mais algumas horas, pois demandava a presença de "especializada", ${ }^{13}$ implicava a retirada de muita arma, munição, busca de papéis, documentos, computadores, podendo levar "o dia todo".

Mesmo não sendo possível estabelecer o mesmo tipo de discurso legitimador observado com o td, o coordenador também utilizou o ta para "comprovar a eficácia do sistema". Segundo ele, no modelo antigo de solicitação, despacho e atendimento, veríamos que o menor daqueles 12 ta apresentaria números muito superiores, segundo ele, às oito horas e 40 minutos da inscrição que aparecia no topo da lista. Para embasar sua resposta, detalhou as diversas agências e instituições que podem ser chamadas em uma ocorrência (PM, Polícia Civil, perícia, CET-Rio, ambulância, delegacia especializada, corpo de bombeiros), afirmando que no modelo antigo não iam partilhar as informações, dificultando o trabalho em conjunto e causando, na maior parte das vezes, mobilização excessiva ou deficitária de "recursos materiais e humanos". Em meio às principais vantagens do modelo do CICC, segundo ele, estariam a possibilidade de otimizar o atendimento - reduzindo o ta, mesmo que isso não possa ser demonstrado com a objetividade que permite o tempo médio de despacho - e o uso desses recursos materiais e humanos por parte dessas agências e instituições, mencionando, sem maior desenvolvimento, a economia financeira que isso propiciaria ao estado.

\section{FORMALIZAÇÃO E INSCRIÇÃO}

O Cuca foi uma das primeiras medidas realizadas pela Secretaria Especial de Ordem Pública (Seop) em 2009. O ambicioso programa procurava, pela primeira vez no Rio de Janeiro, estabelecer as bases para a unificação do registro de todos os vendedores ambulantes da cidade, incluindo inicialmente o recadastramento para 4.000 vendedores já registrados e, numa segunda fase, a abertura de mais 14.400 vagas para novos solicitantes. O número de autorizações para compra e venda em logradouros públicos - Taxa de Uso em Área Pública (Tuap) - era determinado até então pela chamada lei dos ambulantes (I876/I992), restringindo-se a 18.400 . Segundo dados da própria Seop, porém, mais de 35.000 pessoas tentaram cadastrar-se, com 25.000 aprovadas e apenas 18.400 acessando as concessões emitidas. ${ }^{14}$ As autorizações incidiam sobre diferentes tipos de venda em logradouros públicos: bancas de jornal, chaveiros, quiosques de plantas, ambulantes de asfalto e de praia, entre outros. O cadastro permitia a construção de equivalência dessas diferentes atividades econômicas, ainda que cada um desses mercados tenha especificidades em suas formas de organizar a venda dos mais variados produtos. 
A reunião dessas diversas atividades e a restrição das concessões em um único cadastro teve por referência as tipificações incluídas na lei I876/ı992, que serviram de base para estipular os critérios cadastrais de concessão do registro municipal da venda em logradouros públicos. Para conseguir selecionar os contemplados, dados a diversidade e o fato de que o número de solicitantes era muito superior ao fixado em I992, o cadastro funcionou em um sistema de pontuação, que considerava, entre outros critérios, a ordem de prioridade para a concessão pela idade do vendedor, a antiguidade na função, a condição física, a situação penal, o estado civil e o número de filhos. O programa que orientou os critérios considerava todas essas diferentes atividades de compra e venda na rua anteparos ao grande contingente de desempregados e à desorganização urbana; contava, portanto, que essas atividades fossem temporárias e devessem priorizar pessoas com mais dificuldades em acessar o mercado de trabalho assalariado. Uma diferença importante do momento de implementação do Cuca frente aos outros cadastros anteriores é que os contemplados foram orientados, muitas vezes no próprio local em que faziam a inscrição municipal, a realizar um segundo cadastro, uma inscrição federal de empresariamento, estabelecida em dezembro do ano anterior por meio da portaria I 28 de 2008. O microempreendedor individual (MEI) é uma figura do código civil que permite às empresas dessa natureza o acesso a benefícios sociais, como a aposentadoria. Esse segundo cadastro apontava, sem se contrapor, para outro programa, que visava fortalecer o comércio de rua, imaginando as potencialidades dos ambulantes como empreendedores e estimulando sua permanência nessas atividades por meio de referência à forma empresa. O que aconteceu com os vendedores ambulantes a partir do Cuca foi, contudo, menos uma oposição de programas e mais uma sobreposição de cadastros (Hirata, 20I4a). A formalização, portanto, contemplava a combinação de elementos heterogêneos para se concretizar enquanto programa.

Tão importante quanto o programa que assentava os critérios e os que norteavam os cadastros é a forma como foram implementados. Historicamente, os cadastros haviam sido feitos, sobretudo nos chamados camelódromos, pelas associações em conjunto com a prefeitura (agora também com o governo federal). A operacionalização da construção dos cadastros dependia conjuntamente das atividades de associações e funcionários da prefeitura, por meio de listagens que eram repassadas de lado a lado. Quando o Cuca foi proposto, a tentativa era de fazer o cadastramento exclusivamente por funcionários da prefeitura, com vistas a acabar com o que era concebido como clientelismo entre as associações e seus associados. Uma questão central para entender esse ponto é que as associações são, a um só tempo, agentes políticos e econômicos, pois disputam o espaço de negociações com os poderes oficiais mediante diferentes modelos de negócios (Rabossi, 20 I I). O modelo de negócio pode estar em alinhamento ou em conflito com aqueles que a prefeitura ou o governo federal imaginam em seus programas. Às vezes, esses dois cadastros se associam, ganhando mais força, às vezes se 
chocam, abrindo fricções que os enfraquecem. Dessa forma, o alinhamento político e econômico é indissociável e, por essa razão, os cadastros são impulsionadores das relações entre ambulantes e suas associações, a prefeitura, o governo federal, mas também os partidos políticos, as polícias, as organizações criminosas, os fiscais, o Sebrae, os bancos e as diferentes organizações de crédito (Hirata, 20I4b). Os cadastros criam e desfazem, portanto, as associações que organizam igualmente o jogo político e econômico da atividade da venda ambulante.

Essa construção do Cuca materializou os enunciados de apelo à eficácia que marcaram a gestão de Eduardo Paes na prefeitura carioca (Vainer, 20 I I). O argumento da eficácia era duplo: por um lado aumentaria a possibilidade de concessão por meio de critérios "iguais e universais", longe do que se via como a lógica da clientela das associações, e por outro porque permitiria melhor controle sobre os vendedores ambulantes após o registro do Cuca, por via de um sistema unificado. Para tanto, o sistema foi construído mediante registro presencial dos ambulantes em formulário e, posteriormente, na digitação dos formulários em uma base eletrônica especialmente desenvolvida para esse fim.

Cabe relembrar que, anteriormente, o registro era feito por meio de listagens construídas nas associações, mas em seguida encaminhado de forma descentralizada por Região Administrativa (RA) a alguma das I9 Inspetorias Regionais de Licenciamento e Fiscalização (IRLF). Como os registros não eram encaminhados a nenhum órgão centralizador, como a Coordenação de Licenciamento e Fiscalização (CLF), mantinham-se desconectados, de forma que impossibilitava a contabilização da totalidade das licenças municipais, bem como seu uso pela Coordenação de Controle Urbano (CCU), órgão responsável pela fiscalização nas ruas. Dessa maneira, não se sabia ao certo a quantidade de vendedores ambulantes formalizados na cidade do Rio de Janeiro, e o controle era feito com base na apresentação das Tuaps diretamente nas ruas. A dificuldade começava na maneira pela qual a inscrição era realizada, em regra "à mão" e sem muito controle acerca dos critérios utilizados para sua concessão, ainda que esses fossem regulamentados pela lei I876/I992. Essas dificuldades se ampliavam na construção de arquivos em papel, que se mantinham catalogados nas IRLFs, sem ser compartilhados com nenhum outro órgão municipal de atividades associadas. Os agentes da CCU verificavam as Tuaps em cada ponto de venda, seguindo a atualização de seu pagamento anual.

O Cuca mobilizava o uso de novas formas de cadastramento, apoiadas na construção direta pelos agentes da prefeitura e que alimentavam um sistema informatizado que engendrava um banco de dados centralizados com todos os registros municipais gerados individualmente, para cada vendedor. As possibilidades de controle que o Cuca produziu também se apoiavam sobre a construção da Seop, cujo novo design institucional implementava a coordenação como técnica de governo (Hirata \& Cardoso, 20I6) integrando a CLF, a CCU e a Guarda Municipal (GM). A sistematização dessa base de dados foi realizada por meio de gráficos, 
tabelas e do geoprocessamento dos ambulantes, permitindo, assim, controle mais rigoroso das atividades de compra e venda em logradouros públicos. O controle poderia ser feito diretamente na base de dados construída, de modo a dispensar os papéis preenchidos “à mão". Além disso, essa sistematização permitiu o "controle do próprio controle" via GM e CCU, pois exibia claramente os assentamentos de venda ambulante, orientando o trabalho desses atores e tornando objetiva a função a ser desempenhada.

Embora a análise das consequências do Cuca ultrapasse o escopo deste artigo, cabe destacar que a maneira pela qual a inscrição municipal foi feita a partir desse mecanismo alterou as conexões até então operadas pelos cadastros. A etnografia feita no Mercado Popular da Uruguaiana nos permite dizer, contudo, que essas novas conexões estabelecem outra rede político-econômica, ainda que o sistema de listagens tenha sido comum no processo de implementação do Cuca. As continuidades e rupturas desse processo têm relação com o jogo de oposições e complementariedades das diferentes maneiras de formalizar o informal e iluminam o modo como esse tipo de articulação sociotécnica se organiza, ou seja, durante certo tempo a partir de uma concepção centrada na desorganização do mundo do trabalho e do mundo urbano, em seguida articulado às oportunidades de empreendedores. Em cada um desses momentos, a rede que delineia as características da formalização e as faz funcionarem de forma estável se sobrepõe a outras redes, conectando elementos distintos. O resultado, a "inscrição", deve, portanto, ser o final de um percurso de pesquisa e não seu início. A distinção entre os procedimentos do Cuca de formalização dos ambulantes em relação àqueles realizados anteriormente deve ser pensada como parte da estabilização de uma rede de atores heterogêneos que ocorre em um contexto de crise, um momento crítico, que estabelece oposições e posições novas a ser inscritas.

\section{CONCLUSÃO}

Neste artigo, procuramos apontar possibilidades analíticas de aproximação entre Foucault e a ANT, a partir de questões empíricas que emergiram em nossos trabalhos de campo. A noção de "inscrição" foi o ponto de articulação teórico, empírico e tecnológico desse nosso percurso, que permitiu relacionar o tempo de atendimento e de despacho no CICC com o novo cadastramento dos vendedores ambulantes, promovido pela Seop. A inscrição não é somente o meio ou o veículo pelo qual as formas governamentais ganham expressividade, mas é a mediação que constrói estas últimas como fenômeno possível. Dessa maneira, as inscrições podem ser postos de observação (Telles, 2009) que nos ajudem a compreender o governo do conflito nas cidades ou a construção das técnicas de ordenamento urbano.

Ao atentar para as questões práticas envolvidas na produção dessas inscrições pudemos também acompanhar parte de uma das principais tarefas de um "governo" contemporâneo - a construção da "ordem pública". Em linhas ge- 
rais, argumentamos que a "ordem pública" pode ser pensada de forma semelhante, seja como uma rede instável, temporária e em constante recomposição, formada por heterogeneidades e suas relações ou como o objetivo buscado por um amplo e compósito dispositivo de ordenamento público. O uso dos conceitos, da metodologia e do léxico da ANT ou de Foucault nos leva por caminhos bastante próximos e nos permite, da mesma maneira, perceber o poder como um efeito que emerge de uma situação estratégica complexa (Foucault, I979), ou de um conjunto de variadas e exitosas estratégias para envolver os outros (Latour, I986). E, por consequência, nos leva a pensar a "ordem pública" como um efeito almejado de poder - ou, mais precisamente, de saber-poder - e não apenas como a repressão ou contenção de uma série de comportamentos e situações encontradas no espaço urbano. O ordenamento público é uma positivação.

As inscrições - foi o que mostramos a partir dos exemplos etnográficos são parte constitutiva dessas estratégias, redes e dispositivos, seja a partir do saber que produzem, das metas e tecnologias que põem em funcionamento ou das categorias e equivalências que criam e transformam em norma. Em outras palavras, permitem, de acordo com a governamentalidade neoliberal, transformar "multidões confusas" em "multiplicidades ordenadas", conformando os sentidos móveis da ordem urbana. As diversas formas de produzir inscrições - estatísticas, mapas, cadastros ou tempo cronometrado - traduzem uma série de heterogeneidades em normas e autorizações, que regulam e organizam, e também em números, que as abrem para a equalização, comparação, estipulação de metas e aferição de eficácia. Assim, a partir do "desdobramento etnográfico" dos dispositivos e estratégias de inscrição e da continuação dos diálogos com Foucault, com a teoria ator-rede e entre eles, pretendemos continuar pensando e pesquisando a construção do Estado, do governo e da cidade e, dessa forma, a gestão dos territórios urbanos e de seus habitantes.

Recebido em 23/oI/20I7 | Revisto em 08/04/20I7 | Aprovado em I I/04/20I7 
Bruno Cardoso é professor do Programa de Pós-Graduação em Sociologia e Antropologia e do Departamento de Sociologia da UFRJ, pesquisador da Rede Latino-Americana de Estudos sobre Vigilância, Tecnologia e Sociedade (Lavits) e coordenador de pesquisa no Núcleo de Estudos da Cidadania, Conflito e Violência

Urbana (Necvu/UFRJ). Desenvolve pesquisas sobre os temas: tecnologias de segurança, cibercultura, relações de poder, governamentalidade e gestão urbana. É autor de Todos os olhos: videovigilâncias, voyeurismo e (re)produção imagética (20I4).

Daniel Hirata é professor do Departamento de Sociologia e Metodologia em Ciências Sociais, do Programa de Pós-Graduação em Sociologia e do Programa de Pós-Graduação em Sociologia e Direito da UFF. É também pesquisador associado do Núcleo de Pesquisas em Economia e Cultura (NuCEC/UFRJ/MN) e coordenador de pesquisa no Núcleo de Estudos da Cidadania, Conflito e Violência Urbana (Necvu/UFRJ). Desenvolve pesquisas sobre mercados ilegais, informais e ilícitos e formas de controle social. 


\section{NOTAS}

I O Teleatendimento Integrado de Demandas Emergenciais é o software utilizado pela Polícia Militar do Rio de Janeiro para o recebimento de chamadas pela hotline (I9O) e para o despacho de viaturas e acompanhamento de ocorrências.

2 Dentre as pesquisas empíricas que organizam a apresentação de seus dados e extraem consequências analíticas desse debate, destacamos o caso da "batalha dos sistemas" entre Thomas Edison e Nikola Tesla (Mitchell, 2008).

3 Ou aquilo que Deleuze (2005) identifica na obra foucaultiana como "diagrama", embora esse conceito apareça de forma apenas marginal na obra de Foucault.

4 Como salienta Callon (I986), o conceito de "tradução" é cunhado por Serres (1974), sofrendo entretanto modificações a partir de sua adoção pela ANT. Seria impossível, no âmbito do presente artigo, tratar dessas diferenças.

5 No Brasil, há importante bibliografia que vem tratando da antropologia das práticas de poder e da administração pública, também da importância dos documentos em tais práticas. Haveria toda uma interface de nossa perspectiva com essa discussão, muito mais antiga, e que em parte parece inspirar-se no trabalho de Michel Foucault. Ver Souza Lima (2002); Castilho, Souza Lima \& Teixeira (2014); e Lowenkron \& Ferreira (2014). Para uma discussão fora do Brasil, ver Hull (2012) e Riles (2006). Agradecemos a Adriana Vianna as sugestões.

6 Seria de interesse uma aproximação de toda essa discussão, de forma mais pormenorizada, à luz das afinidades com o conceito de "performidade", desenvolvido por Callon (I998a). Contudo, dado o impacto do conceito, deixaremos essa discussão para outro texto.

7 Sobre o conceito de "ponto de passagem obrigatório", Law (I998: 7I) explica que "o ator que é capaz de forçar outros atores a mover-se ao longo de canais particulares e obstruir o acesso a outras possibilidades é um ator que se pode impor a esses outros". Ver também Latour (200I).

8 Embora o termo dispositivo, em sua concepção foucaultiana, fosse utilizado pela ANT em alguns de seus textos seminais (Law, I986), posteriormente vai sendo deixado 
de lado, até ser substituído, na obra de Callon pelo menos, pelo termo "agenciamento" (ver Deleuze \& Guattari, 2007). Para uma explicação detalhada dessa mudança, ver a parte final de Callon (2013).

9 A ação, para os autores da ANT, não pode ser resumida a um momento específico, mas deve ser pensada como distribuída no tempo e no espaço, por intermédio de uma diversidade de atores heterogêneos organizados em rede.

Io Para a ANT, ator é todo elemento que faz alguma diferença no curso da ação, independente de sua figuração, ou seja, se parece ou não com um agente. Com isso, sua lista de atores é bastante mais ampla do que a da maior parte dos sociólogos.

I I Para uma descrição da estrutura do CICC e do modelo que veio substituir, ver Cardoso (2014; 2016).

I2 Não estamos dizendo com isso que apenas os bancos de dados do CICC e da Seseg são alimentados com esses dados, sendo possível também que fiquem à disposição da Geocontrol e de outras empresas ou instituições "parceiras". O crescente comércio de metadados (Big Data), embora de grande interesse, não será abordado no presente artigo.

I3 Delegacia de Repressão a Ações Criminosas Organizadas (Draco).

I4 Consultar:<http://www.rio.rj.gov.br/web/seop/exibeconteudo ?article-id=I740822>. Dados do Dhesca e do Comitê Popular da Copa e das Olimpíadas no Rio de Janeiro sistematizados no relatório "violações do direito ao trabalho e do direito a cidade dos camelos do Rio de Janeiro", apoiados em levantamento do Movimento Unido dos Camelôs (Muca), calculam em 60.000 os ambulantes existentes na cidade. 


\section{REFERÊNCIAS BIBLIOGRÁFICAS}

Bloor, David. (2008). Conhecimento e imaginário social. São Paulo: Ed. Unesp.

Callon, Michel. (2013). Qu'est-ce qu'un agencement marchand? In: Callon, Michel et al. (orgs.). Sociologie des agencements marchands. Paris: Presses des Mines, p. 325-440.

Callon, Michel. (I998a). The law of the markets. Oxford: Blackwell publishers.

Callon, Michel. (I998b). El proceso de construcción de la sociedade. El estudio de la tecnología como herramienta para el análisis sociológico. In: Domenèch, Miquel \& Tirado, Francisco Javier (orgs.). Sociología simétrica: Ensayos sobre ciência, tecnologia y sociedade. Barcelona: Gedisa Editorial, p. I43-I70.

Callon, Michel. (I986). Some elements of a sociology of translation: domestication of the scallops and the fishermen of St Brieuc Bay. In: Law, John (org.). Power, action and belief: a new sociology of knowledge? London: Routledge, p. 196-223.

Callon, Michel. (1979). Les actions concertées chimie macromoléculaire. La socio-logique d'une agence de traduction. Paris: CSI-DGRST-CNRS.

Callon, Michel \& Latour, Bruno. (I98I). Unscrewing the Big Leviathan: or how actors macrostructure reality, and how sociologists help them to do so? In: Knorr, Karin \& Ciccourel, Aaron (orgs.). Advances in social theory and methodology. Towards an integration of micro and macro sociologies. London: Routledge, p. 277-303.

Cardoso, Bruno. (20I6). Tecnopolíticas de integração: ação distribuída, condução de condutas e transformações na segurança pública. In: Silva, Andreia; Dias, Paulo \& Silva, Vania. (orgs.). Conectando mundos, repensando relações. Porto Alegre: Unioeste/Evangraf, p. 37-56.

Cardoso, Bruno. (20I4). Todos os olhos: videovigilâncias, voyeurismo e (re)produção imagética. Rio de Janeiro: Ed. UFRJ.

Castilho, Sérgio; Souza Lima, Antônio Carlos \& Teixeira, Carla Costa. (20I4). Antropologia das práticas de poder: reflexões etnográficas entre burocratas, elites e corporações. Rio de Janeiro: Contracapa. 
Clausewitz, Carl von. (1955). De la guerre. Paris: Éditions de Minuit.

Dean, Mitchell. (1999). Governamentality: power and rule in modern society. London: Sage Publications.

Deleuze, Gilles. (2005). Foucault. São Paulo: Brasiliense.

Deleuze, Gilles \& Guattari, Félix. (2007). Mil platôs: capitalismo e esquizofrenia - vol. I. São Paulo: Ed. 34.

Desrosières, Alain. (I993). La politique des grands nombres. Paris: La Découverte.

Fonseca, Marcio. (2002). Michel Foucault e o direito. São Paulo: Max Limonad.

Foucault, Michel. (2008). Nascimento da biopolítica. São Paulo: Martins.

Foucault, Michel. (2004). Sécurité, territoire, population. Paris: Gallimard/Seuil.

Foucault, Michel. (2003). Vigiar e punir: nascimento da prisão. Petrópolis: Vozes.

Foucault, Michel. (I999). Em defesa da sociedade. São Paulo: Martins Fontes.

Foucault, Michel. (1997). Polémique, politique et problématisation. In: Dits et écrits. Paris: Gallimard, p. 59I-598 (vol. IV).

Foucault, Michel. (1985) História da sexualidade. vol. I: A vontade de saber. São Paulo: Graal.

Foucault, Michel. (1979). Nietzsche, a genealogia e a história. In: Microfísica do poder. Rio de Janeiro: Graal.

Hirata, Daniel. (2014a). Street commerce as a "problem" in the cities of Rio de Janeiro and São Paulo. Vibrant, II/I. Disponível em <http://www.vibrant.org.br/issues/vi InI/daniel-hirata-street-commerce-as-a-problem-in-the-cities-of-rio-de-janeiro-and-sao-paulo/>. Acesso em I8 abr. 2017. Hirata, Daniel. (2014b). Comércio ambulante no Rio de Janeiro e em São Paulo: grupos de poder e instrumentos contemporâneos de governo. In: Dispositivos urbanos e trama dos viventes. Rio de Janeiro: Ed. FGV.

Hirata, Daniel \& Cardoso, Bruno. (20I6). Coordenação como técnica de governo. Horizontes Antropológicos, 22/46, p. 97-130. 
Hughes, Thomas. (I986). The seamless web: technology, science, etcetera, etcetera. Social Studies of Science, I6/2, p. 28I-292.

Hughes, Thomas. (1983). Networks of power: electrifications in Western society (I880-1930). London \& Baltimore: John Hopkins University Press.

Hull, Matthew. (2012). Documents and bureaucracy. Annual Review of Antropology, 4I, p. 25I-267.

Latour, Bruno. (20I2). Reagregando o social: uma introdução à teoria do ator-rede. Salvador/Bauru: Edufba/Edusc.

Latour, Bruno. (20II). Ciência em ação: como seguir cientistas e engenheiros sociedade afora. São Paulo: Ed. Unesp.

Latour, Bruno. (200I). Pasteur: guerre et paix des microbes. Paris: La Découverte.

Latour, Bruno. (I986). The powers of association. In: Law, John (org.). Power, action and belief: a new sociology of knowledge? London: Routledge.

Latour, Bruno \& Woolgar, Steve. (1997). A vida de laboratório: a produção dos fatos científicos. Rio de Janeiro: Relume Dumará.

Law, John. (2012). Technology and heterogeneous engineering: the case of portuguese expansion. In: Bijker Wiebe; Hughes, Thomas \& Pinch, Trevor (orgs.). The social construction of technological systems: new directions in the sociology and history of technology. Cambridge/London: The MIT Press, p. I05-I27.

Law, John. (2002). Aircraft stories: descentering the object in technoscience. Durham: Duke University.

Law, John. (I998). Del poder y sus tácticas. Un enfoque desde la sociologia de la ciência. In: Domenèch, Miquel \& Tirado, Francisco Javier (orgs.). Sociología simétrica: ensayos sobre ciência, tecnologia y sociedade. Barcelona: Gedisa Editorial, p. 63-107.

Law, John. (I986). On the methods of long distance control: vessels, navigation, and the Portuguese route to India. In: Law, John (org.). Power, action and belief: a new sociology of knowledge? London: Routledge, p. 234-263.

Lowenkron, Laura \& Ferreira, Letícia. (2014). Antropological perspectives on documents. Vibrant, II/2, p. 75-III. 
Miller, Peter \& Rose, Nikolas. (20I2). Governando o presente. São Paulo: Paulus.

Mitchell, Timothy. (2008). Rethinking economy. Geoforum, 39, p. III6-II2I.

Rabossi, Fernando. (20II). Negociações, associações e monopólios: a política da rua em Ciudad del Este (Paraguai). Etnográfica, I5/ı, p. 83-107.

Riles, Annelise. (2006). Documents. Michigan: The university of Michigan press.

Serres, Michel. (I974). Hermès III: la traduction. Paris: Editions de minuit.

Shapin, Steven. (20I4). Une histoire sociale de la verité: science et modernité dans l'Angleterre du XVII siècle. Paris: La Découverte.

Souza Lima, Antônio Carlos. (org.). (2002). Gestar e gerir: estudos para uma antropologia da administração pública no Brasil. Rio de Janeiro: Relume Dumará.

Telles, Vera. (2009). Ilegalismos urbanos e a cidade. Novos Estudos - CEBRAP, 84, p. I53-I73.

Thévenot, Laurent. (I986). Les investissement de forme. In: Conventions économiques. Paris: PUF, p. 2I-7I.

Vainer, Carlos. (20II). A cidade de exceção: reflexões a partir do Rio de Janeiro. Anais do XIV Encontro Nacional da Associação Nacional de Planejamento Urbano (Anpur), v. I4. 
Palavras-chave

Governamentalidade; teoria do ator-rede; procedimentos de inscrição; mercado informal;

Foucault.

Keywords

Governmentality; actor-network theory; inscription procedures; informal market;

Foucault.

\section{DISPOSITIVOS DE INSCRIÇÃO E REDES DE} ORDENAMENTO PÚBLICO: APROXIMAÇÕES ENTRE A TEORIA DO ATOR-REDE (ANT) E FOUCAULT

\section{Resumo}

Este artigo discute o conceito de inscrição por meio de uma aproximação de pesquisas desenvolvidas no Centro Integrado de Comando e Controle e na Secretaria Especial de Ordem Pública, órgãos da administração municipal e estadual, respectivamente, da cidade e do estado do Rio de Janeiro. Indicamos como subjaz à construção desse conceito nas abordagens utilizadas nessas pesquisas uma convergência teórica e metodológica com as concepções de poder em Michel Foucault e com aquelas existentes na teoria do ator-rede.

\section{INSCRIPTION DEVICES AND PUBLIC ORDER} NETWORKS: CONVERGENCES BETWEEN ACTOR-NETWORK THEORY (ANT) AND FOUCAULT

\section{Abstract}

This article discusses the concept of inscription through an examination of studies developed at the Integrated Command and Control Centre and at the Special Secretariat of Public Order - municipal and state public authorities, respectively, of the city and state of Rio de Janeiro. The text shows how the construction of this concept in these studies is informed by an underlying theoretical and methodological convergence between the conceptions of power in Michel Foucault and those posited by actor-network theory. 